\title{
“Ciudades fantasma” en el entorno del Área Metropolitana de Madrid (España). Un análisis de la Región de Castilla-La Mancha
}

Maria-Carmen Cañizares. Universidad de Castilla-La Mancha, Ciudad Real, España. María-Ángeles Rodríguez-Domémech. Universidad de Castilla-La Mancha, Ciudad Real, España.

RESUMEN | En el contexto de las nuevas formas de urbanización irracional, analizamos el fenómeno de las "ciudades fantasma" en España, consecuencia del periodo de urbanismo expansivo anterior a la crisis económica global de 2008. Convertidas en espacios inconclusos a partir de ella, han cobrado protagonismo en el periodo poscrisis. El objetivo es presentar algunos casos españoles vinculados con el área metropolitana de Madrid dentro de la Comunidad Autónoma de Castilla-La Mancha: El Quiñón en Seseña (Toledo), Ciudad Valdeluz en Yebes (Guadalajara) y El Reino de Don Quijote en Ciudad Real (Ciudad Real). La metodología combina aspectos cualitativos relativos a la descripción de los casos de estudio con otros cuantitativos, basados en estadísticas sobre población y viviendas. Los resultados permiten enmarcar los ejemplos escogidos en las dinámicas del urbanismo expansivo, ya que sirven para ilustrar prácticas urbanísticas alejadas de la sostenibilidad.

PALABRAS CLAVE | crecimiento urbano, mercado inmobiliario, urbanismo.

ABSTRACT | In the new forms of irrational urbanization context, this work addresses the phenomenon of the "ghost cities" in Spain, a consequence of the period of expansive urbanism prior to the global economic crisis (2008). Transforming into unfinished spaces from it, they have had leading part in the post-crisis period. The objective is to present some Spanish cases near Madrid metropolitan area within the autonomous community of Castilla-La Mancha: El Quiñon in Seseña (Toledo), Ciudad Valdeluz in Yebes (Guadalajara) and El Reino de Don Quijote in Ciudad Real (Ciudad Real). The methodology combines qualitative aspects related to the description of the case studies with other qualitative methods based on statistics on population and housing. The results allow framing the examples chosen in the dynamics of expansive urbanism as they serve to illustrate urban practices away from sustainability.

KEYWORDS | urban growth, real estate market, urbanism.

Recibido el 31 de octubre de 2018, aprobado el 5 de abril de 2019.

E-mails: M.-C. Cañizares, mcarmen.Canizares@uclm.es|M.-A. Rodríguez-Domémech,mangeles.Rodríguez@uclm.es 


\section{Urbanismo expansivo y "ciudades fantasma”: singularidades del caso español}

En el tránsito desde el siglo pasado al actual, diferentes países del mundo han visto consolidarse nuevas formas de urbanización en el marco de crecimientos urbanos descontrolados e irracionales que, claramente, se han materializado en desarrollos insostenibles (Rullán, 2012; Valenzuela, 2016). Este fenómeno global, asociado a la especulación del suelo ha tenido repercusiones muy evidentes, que se han concretado en las denominadas "ciudades fantasma" o ghost towns (también denominadas ghost cities). Definidas como producto de aquel desarrollo urbano que está funcionando con una menor capacidad de personas y empresas respecto al que fue diseñado (Shepard, 2015), a ellas se vinculan, lógicamente, numerosas viviendas vacías, fenómeno que ha atraído la atención científica, la de los medios de comunicación y la de algunos gobiernos (Zheng et al., 2017). Tienen su origen en la primera década del siglo xxi, cuando las expectativas de crecimiento no auguraban los efectos que la crisis económica mundial, iniciada en 2008, iba a dejar en estos espacios. En ellas es reconocible su origen localizado, mientras sus efectos y consecuencias también presentan connotaciones territoriales específicas (Daher, 2013). Y si bien Europa Occidental y Estados Unidos fueron escenario de los procesos más relevantes, esta forma de urbanismo expansivo se extendió a otros territorios, como México, Brasil y Chile en América Latina, junto con China, India o Corea de Sur en Asia.

Siguiendo a López Moreno y González Blanco (2014, p. 208 y ss.), encontramos manifestaciones singulares de estas ciudades fantasma en Europa, donde países como Irlanda y Espańa construyeron, antes de la crisis, más del doble de viviendas por habitante respecto a otros países europeos, fruto de la bonanza económica y del boom inmobiliario, proceso extensivo a Portugal, Grecia o Italia, principalmente. Fueron desarrollos sobredimensionados que generaron un importante parque de viviendas, vacías, situación que afloró una vez destapada la crisis. En Estados Unidos -año 2011 y superada la fiebre constructora-, se llegó a contabilizar más de 11 millones de viviendas vacías, cuando solo un tercio de ellas hubiera cubierto las necesidades de vivienda de aproximadamente 3,5 millones de personas sin hogar. En América Latina el fenómeno se manifestó de manera más pronunciada en países en los que el sector de la construcción se había fortalecido durante la última década, como México, donde casi 5 millones de casas quedaron deshabitadas en 2010. López y González (2014, p. 211) señalan al respecto que ello ocurrió sobre todo en estados fronterizos, como Baja California, Chihuahua, Zacatecas y Tamaulipas, en los que la tasa de viviendas desocupadas superó el 18\%, a pesar de la recesión económica. Ese mismo año, agregan, se contabilizaron en Brasil más de 6 millones de viviendas, la mayoría localizadas en zonas urbanas, entre las que destacan São Paulo y Minas Gerais. Por su parte, Chile y Venezuela muestran tasas del 9,6\% y 7,7\% de viviendas desocupadas, respectivamente, aunque en casos como Valparaíso, según señalan, ello se debió en parte a la existencia de segundas residencias. Para Aalbers (2016) y De Mattos $(2015,2016)$, todos los señalados son aspectos vinculados con las dinámicas financieras globales y el impacto urbano de las estrategias de valorización del capital excedente surgido de los circuitos financieros mundiales, es decir, con la "financiarización" de los distintos procesos que tienen lugar en espacios urbanos. 
Finalmente, en el sudeste asiático destaca China, ya que, fruto de la política urbana nacional (Zheng et al., 2017, p. 112), es el país con mayor incremento de ciudades sin habitantes (Shepard, 2015). El consumo de suelo y los vacíos demográficos han sido allí la clave del urbanismo expansivo (Batty, 2014, 2016), consecuencia de desarrollos inmobiliarios nuevos a gran escala que no integran al tejido social y mantienen precios muy altos (Duhamel \& Trápaga, 2015, p. 94).

Las transformaciones urbanas del último medio siglo en España han tenido indudables efectos positivos, aunque también han generado importantes retos. El proceso de urbanismo expansivo vivido desde mediados de los años noventa del siglo pasado ha presentado cierta singularidad. El notable aumento del número de viviendas y la burbuja inmobiliaria generada, la crisis económica posterior y los numerosos espacios urbanos inconclusos resultantes (vacíos urbanos), han despertado el interés de diversos geógrafos (Brandis, 2012; Burriel, 2008, 2014, 2016; Calderón, 2004; Capel, 2009; 2013; Cebrián, 2007, 2013; Lois, Piñeira, \& Vives, 2016; Méndez, 2012; Méndez, Abad, \& Echaves, 2015; Romero, 2010; Rullán, 2012, 2016; Valenzuela, 2013, 2016; Valenzuela \& Salom, 2008; Vives \& Rullán, 2014), en el marco de una "geografía urbana renovada" (Delgado, 2016, p. 126 y ss.). También el de autores de otras disciplinas (Delgado, 2016, p. 126 y ss.), que han ofrecido perspectivas complementarias para analizar un fenómeno sin precedentes del que debería quedarnos alguna enseñanza, para no repetir los mismos errores en el futuro y actuar con un mayor respeto por el territorio.

Para diversos autores, el urbanismo expansivo es, desde el punto de vista ideológico, un proceso claramente vinculado con las políticas neoliberales y, en consecuencia, con el denominado "giro neoliberal" aplicado a las políticas de la ciudad. Su apuesta por la producción inmobiliaria como motor de la actividad económica, junto con la liberalización y revalorización del suelo favorecidas por la legislación urbanística, se ha plasmado en urbanización masiva y dispersa con grandes desarrollos fuera de la planificación. El resultado de este capitalismo desregulado ha sido una aceleración, sin precedentes, de la expansión urbana y de las dinámicas de artificialización del suelo (Lois, et al., 2016). Ejemplo de urbanismo neoliberal (Peck, Theodore, \& Brenner, 2009), a él se ha unido un gran número de desahucios inmobiliarios, con consecuencias sociales dramáticas (Méndez \& Plaza, 2016). Además, se trata de una práctica que ha desempeñado un papel esencial en el aumento de la conectividad y de la movilidad, lo cual ha desencadenado una importante metamorfosis de las áreas urbanas en el mundo (De Mattos, Fuentes, \& Link, 2014, p. 193 y ss.).

El crecimiento de la urbanización en España hasta 2007 "no tiene parangón con ningún otro ciclo descrito hasta el momento, tanto por su duración como por su intensidad" (Rullán, 2012, p. 165). A él han contribuido la facilidad legislativa para transformar en "aptos" suelos no urbanizables, anterior a la Ley del Suelo de 1998; la mejora en las infraestructuras de comunicación y la utilización masiva del automóvil, con el consiguiente incremento de la movilidad; unas condiciones financieras favorables; un valor del suelo más bajo en las periferias; nuevas preferencias sobre la tipología de vivienda, entre otros condicionantes. Todos ellos han consolidado un urbanismo difuso o disperso en ciudades grandes y medianas, claro exponente de la 
denominada "burbuja inmobiliaria", la más larga e intensa de entre las ocurridas en España desde los años ochenta, y acompañada de efectos demoledores (Valenzuela, 2016, p. 226).

Construcción de viviendas e incremento de suelo urbanizable han sido las claves de la "burbuja". Lois, Pińera y Vives (2016, s.p.) señalan al respecto que ha sido una construcción basada en el estímulo a la compra privada "gracias a la reducción de intereses bancarios, el acceso fácil a las hipotecas, la descongelación de los alquileres y la desgravación fiscal por adquisición de una vivienda (tanto si iba a ser ocupada como si no)". Como consecuencia directa, agregan, "se convirtió en suelo urbanizable todo aquel suelo que no tenía un valor especial para ser protegido", proceso muy evidente en algunas de las grandes ciudades del país, como Madrid y Valencia. El incremento del número de viviendas en este intervalo de tiempo, principalmente desde 1996 a 2007, ha estado determinado también por una demanda continua que se ha correspondido con un planeamiento claramente sobredimensionado (Gaja, 2015, p. 121). La proliferación de urbanizaciones definidas por la discontinuidad territorial, que ha calado progresivamente en la forma de construir la ciudad y, con el tiempo, se ha convertido en expresión del paisaje y de los usos de suelo a diferentes escalas (Cebrián, 2013, pp. 25-26), es una de sus manifestaciones más claras.

El proceso descrito constituye un fenómeno que, como hemos señalado, no ha sido exclusivo de España, aunque no existe ningún otro ejemplo, al menos en Europa, en el que la construcción, y el subsector vivienda, hayan alcanzado los niveles cuantitativos y cualitativos del caso español (Fernández-Tabales \& Cruz, 2013 , p. 35). Su singularidad ha radicado en "la particular especialización española en la revalorización de los activos urbanísticos (léase especulación) como base del crecimiento, como base de la formación de la burbuja” (Rullán, 2012, p. 201). Es decir, aquí frecuentemente "la edificación ha estado ligada a la inversión y a la especulación" (Concheiro, 2014, p. 1), configurando una "burbuja especulativa" (Naredo \& Relevante, 2015, p. 77). Su consecuencia más grave ha sido la transformación paisajística de un recurso, el territorio, que presenta gran fragilidad al ser no solo el soporte de nuestras actividades, ni siquiera un activo económico, sino un recurso -insistimos- "no renovable, esencial y limitado, (...) referente de identidad y cultura", que "contiene valores ecológicos, culturales y patrimoniales que no pueden reducirse al precio del suelo", según recoge el Manifiesto "Por una Nueva Cultura del Territorio" (vv.AA., 2006), redactado por un colectivo de geógrafos, urbanistas y arquitectos. En este documento se afirma, también, que las administraciones deben (en teoría) "velar por sus cualidades y potencialidades", siempre teniendo presente que "la apropiación privada de cualquier parte del territorio debe ser compatible con dichos valores", por lo que "la propiedad del suelo y la vivienda debe ser ejercida con respeto de su función social, y con la asunción plena de la responsabilidad de potenciar su utilidad, su valor ambiental y su potencial paisajístico". Es claro su tono de denuncia, cuando ya eran visibles las consecuencias negativas de carácter ambiental 
y paisajístico derivadas de este modelo de urbanización; ${ }^{1}$ un modelo que, plagado de prácticas no siempre correctas, muchas veces opacas y vinculadas con políticas ineficaces, se convirtió en el protagonista de la denominada "década prodigiosa del urbanismo español” (Burriel, 2008), del "tsunami urbanizador” (Fernández, 2006; Gaja, 2008), del "tsunami inmobiliario" (Gaja, 2013; Valenzuela, 2013) o del "urbanismo salvaje" (Valenzuela, 2016, p. 225), maneras de denominar un mismo proceso que contribuyó al "desordenamiento del territorio al dictado de oligarquías político-empresariales” (Naredo, 2010, p. 21). Como resultado, se ha desarrollado gran cantidad de "espacios inconclusos", algunos de los cuales, llenos de viviendas deshabitadas, han dado lugar a verdaderas "ciudades fantasma" (Burriel, 2014, p. 111), como han sido calificadas por la prensa internacional en la búsqueda de un concepto con cierta repercusión social.

Este ciclo expansivo quedaría ralentizado cuando, en el verano de 2007, se derrumbó todo el entramado financiero armado en torno a las llamadas hipotecas subprime (de alto riesgo), génesis de la crisis financiera mundial (Gaja, 2015, p. 120 y s.; Gotham, 2009), jalonada por la quiebra de la banca Lehman Brothers (15 de septiembre de 2008). Una crisis económica que terminó convirtiéndose también en "crisis urbana" (Méndez, Abad, \& Echaves, 2015, p. 42), al iniciarse un periodo de inestabilidad financiera, social, política y económica global que, a nivel de Estado, se tradujo en el agotamiento del modelo de acumulación aplicado en el sector inmobiliario. Sus efectos llegaron a Espańa más tarde, en la medida en que los bienes raíces se hundían de forma más lenta (aunque aún más profunda) que en el resto de Europa (Marichal, 2013, p. 309 y s.). Se trata de un contexto en que han sido las entidades financieras las que han incrementado su hegemonía. En este escenario, los propietarios del suelo se veían desplazados por los promotores en la producción y patrimonialización de las rentas urbanas, que favorecían el llamado "urbanismo concesional" (Vives \& Rullán, 2014, p. 387), a la vez que la "economía del ladrillo" contribuía a potenciar la crisis financiera (Caravaca, González-Romero, \& López, 2017, p. 11). Como consecuencia de este proceso, se constata un elevado número de "trabajadores parados, planes que no se ejecutan y productos que no venden", así como de "viviendas sin gente" (Rullán, 2016, p. 1278 y s.): un modelo expansionista cuyo declive ha estado marcado más por un escenario de cambio financiero que por la preocupación de devolver una política de suelo o vivienda coherente con las necesidades de la mayoría (Lois, Piñeira, \& Vives, 2016; Ocaña, 2009). Fruto de todo ello, nos encontramos con un complicado saldo territorial y urbano, materializado, sobre todo, en salvajes efectos territoriales y ambientales (Valenzuela, 2016, p. 225 y ss.). Afrontar retos como la insostenibilidad urbana y el incremento del transporte para el ciudadano, con elevados costes en nuestra sociedad (Nel.lo, 2017 , p. 334), es ahora lo más importante.

Promovido por el entonces presidente de la Asociación de Geógrafos Españoles, Rafael Mata, (http://www.geografos.org/images/stories/interes/nuevacultura/manifiesto-por-una-nuevacultura-del-territorio-d5.pdf), el Manifiesto tuvo su continuidad en el documento Territorio, urbanismo y crisis, redactado en 2009 (https://nuevaculturadelterritorio.files.wordpress. com/2008/05/territorio_urbanismo_y_crisis.pdf). 
En este marco teórico, las preguntas de investigación que planteamos, para un territorio limítrofe con el área metropolitana de Madrid, son: ¿cómo ha afectado el urbanismo expansivo y la posterior crisis a la región de Castilla-La Mancha? Y ¿son las "ciudades fantasma" en Castilla-La Mancha un resultado suficientemente significativo de unas prácticas urbanísticas inadecuadas a escala nacional?

\section{Nuevos escenarios urbanos antes y después de la crisis en la región de Castilla-La Mancha (España)}

A finales del siglo pasado, algunas de las ciudades más importantes de la Comunidad Autónoma de Castilla-La Mancha, con 2.033.169 habitantes en 2018 (Instituto Nacional de Estadística [INE], 2019), como Toledo, Guadalajara y Ciudad Real, se encontraron entre las quince capitales con mayor incremento de suelo en Espańa (Rodríguez, 2011, p. 596 y s.), beneficiadas por su cercanía y conexión con Madrid, capital del país, especialmente a través de la línea ferroviaria de alta velocidad española (AVE). En esta región, como en muchas otras españolas, la transformación de suelo rural (no urbanizable) en suelo urbanizable y urbano ha sido considerable. No obstante, en Castilla-La Mancha la burbuja inmobiliaria "ha tenido un comportamiento mucho menos acentuado, pero no por ello ha dejado de manifestarse, a distintas escalas", como han demostrado algunos estudios al analizar el incremento en el número de parcelas urbanas y la evolución de la superficie de las mismas, especialmente relevante entre los ańos 2000 y 2008 (Cebrián \& García, 2011, p. 135 y ss.). Lo atestigua, también, el incremento de superficie artificial por habitante que, en las últimas décadas del siglo pasado, era significativo para el conjunto nacional en las ciudades medias con población inferior a 250 mil habitantes y $22 \mathrm{~m}^{2} /$ hab en el periodo 1987-2000. Sobresalen al respecto, en Castilla-La Mancha, algunas de sus capitales provinciales, anteriormente citadas, en las que la suburbanización está más sólidamente estructurada (Cebrián, García, \& Panadero, 2009, p. 125). La cercanía y conexión con Madrid y su corona metropolitana explican que las provincias que progresivamente han ido absorbiendo gran parte de la expansión urbanística de la capital de España, presentaran los incrementos de viviendas más llamativos entre 1996 y 2006, así como los indicadores de viviendas iniciadas por mil habitantes más altos de España en 2006. Es el caso de Toledo, con más de 35 viviendas por mil habitantes, cinco veces el nivel de 1996 (Burriel, 2014, p. 4).

Para explicarlo, a todos los factores generales esgrimidos anteriormente, tanto en el ámbito global como en el local, añadimos la existencia de una legislación regional en Castilla-La Mancha en clara sintonía con la nacional, absolutamente permisiva. Nos referimos a la Ley 2/1998, de 4 de junio, de Ordenación del Territorio y Actividad Urbanística (LOTAU), modificada con posterioridad (2003 y 2005), que facilitó la conversión de suelo rústico en urbanizable. A ella se unió la Ley 2/2009, de 14 de mayo, de Medidas Urgentes en Materia de Vivienda y Suelo, junto con el Texto Refundido de la citada ley (LOTAU) en 2010, que seguía promocionando un urbanismo neoliberal al facilitar la conversión de los suelos rústicos en urbanizables, incluso iniciada la crisis económica mundial. Se trata de avances legislativos que no se han trasladado, de manera generalizada, a la creación/renovación/actualización de 
los Planes de Ordenación Municipal en la mayor parte de las ciudades importantes de Castilla-La Mancha, redundando, todo ello, en el escenario de urbanización expansiva e incontrolada que analizamos (Cañizares \& Rodríguez, 2017, p. 56). Como podemos observar en la tabla 1 , el número de viviendas construidas experimentó un aumento considerable desde 1995 (17.368 viviendas) hasta el año 2007 (67.501), con un máximo el año anterior de 69.869 viviendas (también se constató tal aumento en el número de viviendas rehabilitadas, pero con una dimensión mucho menor); incremento paralelo al del precio medio del metro cuadrado, que pasó de $€ 505,3 / \mathrm{m}^{2}$ en 1995 a $€ 1424,1 / \mathrm{m}^{2}$ en 2007 . A partir de 2008 , y por tanto de la crisis económica, ambos indicadores descendieron de manera significativa, mucho más en el caso de las viviendas construidas que, en el tránsito de 2007 a 2008, se redujeron a la mitad (27.196 viviendas), hasta quedar casi paralizado el sector con 1854 viviendas en 2014, año con los datos más bajos. Este cambio de signo, e incluso de ritmo, está relacionado, lógicamente, con la crisis económica, cuyo calado en Castilla-La Mancha requiere una atención pormenorizada en relación con lo sucedido en España, donde la crisis ha tenido un impacto territorial desigual (Burriel, 2016; Méndez, 2012), ya que las características propias de cada territorio han determinado sus consecuencias y han condicionado su vulnerabilidad. De manera general, en un primer momento (2008), en Castilla-La Mancha, como ocurrió en España, se produjo una restricción del crédito disponible, freno en la compra de viviendas y consiguiente elevación del paro en el sector de la construcción; después, en una segunda fase (2009), la crisis se extendió al resto de actividades y al consumo interno que, a partir de 2010, se completaría con la aplicación de medidas de austeridad impuestas desde la Unión Europea (UE) (Méndez, 2012, p. 41; Méndez et al., 2015, p. 27 y ss.), para asistir a una tímida recuperación en los últimos años, manifestada en un ligero aumento de viviendas después de 2014. Por su parte, el precio medio de la vivienda libre manifiesta un descenso más progresivo y relativamente menor, pasando de $€ 1402,1 / \mathrm{m}^{2}$ en 2008 a $€ 874,2 / \mathrm{m}^{2}$ en 2017.

El boom inmobiliario desencadenó también aquí un gran incremento de suelo urbano, concretamente de un 24\% para el periodo 1996-2006 (Rodríguez, 2014, p. 156). Se trató de una forma de expansión urbana según el modelo de crecimiento periférico disperso o difuso (Cebrián, 2007, 2013), preferentemente "a base de urbanizaciones de gran tamaño, de un único promotor, con una función casi exclusivamente residencial y conectadas a grandes ejes de infraestructuras" (Concheiro, 2014 , p. 5). Entronca, pues, con lo que se ha denominado urban sprawl, desarrollos urbanos de baja densidad que, en los países europeos meridionales, presenta impactos ambientales y económicos severos (Hortas-Rico, 2014, p. 843). 


\begin{tabular}{|c|c|c|c|c|}
\hline \multirow[b]{2}{*}{ AÑo } & \multirow{2}{*}{$\begin{array}{c}\text { POBLACIÓN } \\
\text { N. }{ }^{\circ} \text { HAB. }\end{array}$} & \multicolumn{2}{|c|}{ LICENCIAS DE OBRAS } & \multirow{2}{*}{$\begin{array}{c}\text { PRECIO MEDIO } \\
\text { EUROS/M2 }\end{array}$} \\
\hline & & $\begin{array}{l}\text { VIVIENDAS POR } \\
\text { CONSTRUIR }\end{array}$ & $\begin{array}{c}\text { VIVIENDAS } \\
\text { REHABILITADAS }\end{array}$ & \\
\hline 1995 & 1.692 .678 & 17.368 & 359 & 505,3 \\
\hline 1996 & 1.712 .529 & 12.204 & 336 & 517,2 \\
\hline 1997 & 1.706 .562 & 12.548 & 232 & 529,8 \\
\hline 1998 & 1.716 .152 & 17.496 & 372 & 532,8 \\
\hline 1999 & 1.726 .199 & 17.993 & 236 & 562,3 \\
\hline 2000 & 1.734 .261 & 25.886 & 367 & 607,8 \\
\hline 2001 & 1.755 .053 & 29.505 & 621 & 676,8 \\
\hline 2002 & 1.763 .493 & 27.113 & 374 & 767,2 \\
\hline 2003 & 1.797 .142 & 38.502 & 498 & 874,0 \\
\hline 2004 & 1.833 .549 & 51.259 & 551 & $1.031,4$ \\
\hline 2005 & 1.874 .004 & 65.644 & 528 & $1.233,3$ \\
\hline 2006 & 1.917 .447 & 69.869 & 842 & $1.360,5$ \\
\hline 2007 & 1.971 .222 & 67.501 & 458 & $1.424,1$ \\
\hline 2008 & 2.031 .828 & 27.196 & 450 & $1.402,1$ \\
\hline 2009 & 2.066 .417 & 9.002 & 301 & $1.246,6$ \\
\hline 2010 & 2.084 .470 & 7.565 & 303 & $1.243,1$ \\
\hline 2011 & 2.099 .057 & 5.248 & 246 & $1.173,5$ \\
\hline 2012 & 2.105 .936 & 2.706 & 144 & 1.064 \\
\hline 2013 & 2.094 .391 & 1.977 & 260 & 1.091 \\
\hline 2014 & 2.075 .197 & 1.854 & 125 & 879,1 \\
\hline 2015 & 2.062 .767 & 2.445 & 148 & 891,9 \\
\hline 2016 & 2.048 .900 & 2.766 & 151 & 881,3 \\
\hline 2017 & 2.040 .939 & 2.901 & 171 & 874,2 \\
\hline 2018 & 2.033 .169 & - & - & - \\
\hline
\end{tabular}

TABLA I | Evolución del número de licencias de obra y precio medio del metro cuadrado en Castilla-La Mancha (1995-2018)

FUENTE: instituto NACiONAL DE ESTADística (INE), Ministerio DE FOMENTo (2OI8) y JUNTA DE COMUNIDADES DE CASTILLA-LA MANCHA (JCCM) (2018)

\section{Urbanismo reciente y “ciudades fantasma” en Castilla-La Mancha (España)}

La atención de los medios de comunicación

El concepto de "ciudad fantasma" ha sido utilizado por la prensa internacional y, en menor medida, por la prensa española, para identificar las urbanizaciones "fallidas" como consecuencia de la burbuja inmobiliaria que han caracterizado el urbanismo expansivo en España, y su posterior declive con la crisis económica. La primera referencia es de agosto de 2008, cuando el periodista Hugh Pym de la BвC escogió la macrourbanización "El Quiñón”, localizada en el desolador paisaje urbano de las periferias del municipio de Seseña, provincia de Toledo (Castilla-La Mancha), como ejemplo para describir el freno del negocio inmobiliario en Espańa, que había pasado del auge urbano a las "ciudades fantasma" (McGovern, 2008). Titulares tan 
significativos como "lа ввс descubre la 'ciudad fantasma'"; о comentarios como: "en esta ciudad la población no ha desaparecido, simplemente nunca ha existido", hacían referencia a una realidad que, sin embargo, sabemos que no era exclusiva de este núcleo toledano, sino la "la punta del iceberg" de un proceso de dimensiones más amplias.

Se sucedieron, entonces, artículos que mostraban las diferentes caras del mismo proceso, a modo de ejemplos de "ciudades fantasma" o ghost towns. Entre ellos, el publicado en 2010 por The New York Times (Daley \& Minder, 2010) sobre Ciudad Valdeluz, urbanización localizada en el término municipal de Yebes (Guadalajara) a $8 \mathrm{~km}$ de su cabecera. The Guardian en 2011 incidía, de nuevo, en las ciudades fantasma españolas (Chakrabortty, 2011), mientras que en el diario español El Mundo se afirmaba: "Las ciudades fantasma de la burbuja fascinan a la prensa extranjera" (vv.AA., 2011). "A vista de pájaro", en The Bussines Insider (Goldman \& Lubin, 2011), aportó imágenes de satélite sobre el estado de algunas de las urbanizaciones: Horche, junto a Ciudad Valdeluz, Quer, Alovera y Chiloeches (todas en Guadalajara), Yuncos (Toledo), La Serena (Murcia) o la promoción de Ojo del Salado y Chimborazo, en el distrito del Genil (Granada). A tales casos se podría añadir otros de futuro incierto, como parte del Señorío de Illescas (Toledo), Costa Miño (A Coruña), La Muela (Zaragoza), El Toyo (Almería), Costa Esuri (Ayamonte, Huelva) o La Torre Golf Resort (Murcia). ${ }^{2}$

Con consecuencias medioambientales nefastas, algunos autores clasifican tales ciudades como "atentados urbanísticos al medio ambiente" (Hernández, 2007), los cuales despiertan el interés en ONG como Ecologistas en Acción, que ha cartografiado este tipo de macroproyectos urbanísticos en dos momentos distintos: 2007 y 2012. En el caso de Castilla-La Mancha, no hay registros para 2007 y para el año 2012 aparecen diecinueve casos contabilizados, muchos de ellos paralizados por la crisis.

\section{"Ciudades fantasma" en el entorno del área metropolitana de Madrid}

Estas urbanizaciones tienen una relación directa con los procesos de salida de población del área metropolitana de Madrid, cuyas razones se resumen en "precios más bajos de las viviendas, pero también las nuevas preferencias residenciales por tipologías unifamiliares, núcleos más pequeños, mayor calidad ambiental o tranquilidad, así como la mejora de las comunicaciones" (Burriel, 2008, p. 40), fenómeno relacionado con lo que ya Berry (1976) había definido con contraurbanización (counterurbanization). Además, la conformación de áreas urbanas supramunicipales en el entorno de Toledo y Guadalajara es expresión de dinámicas como la mejora en las comunicaciones por autovía y ferrocarril (AVE) y la aparición de nuevas funciones vinculadas con el terciario especializado (turismo), a las que hay que ańadir los efectos de la deslocalización industrial hacia los respectivos corredores (Cebrián, 2007, p. 238). En el análisis del policentrismo en Castilla-La Mancha, de hecho, las áreas funcionales urbanas localizadas en las zonas de contacto con la Comunidad

La prensa internacional ha prestado también interés a los “aeropuertos fantasma” (Burgen, 2015), de los cuales también Castilla-La Mancha aporta un ejemplo significativo en Ciudad Real. 
de Madrid (Guadalajara, Toledo, Illescas), son las que presentan un mayor dinamismo no solo demográfico sino también socioeconómico, basado, en gran parte, en las buenas conexiones de sus principales ciudades con la capital (Cañizares \& Martínez, 2014; Pillet \& Cañizares, 2017; Pillet et al., 2010; Pillet et al., 2014).

Las ciudades fantasma han surgido a partir de planeamientos urbanísticos basados en la transformación de suelo rústico en urbanizable. Pensados y ejecutados, muchas veces, para ser habitados por miles de familias, en la realidad nunca llegaron a contar con más de unas decenas de vecinos. Han constituido un buen ejemplo de la "producción del espacio urbano" (Capel, 1975, p. 85, citado por Vives \& Rullán, 2014, p. 389) como resultado de las prácticas de algunos agentes que actúan en el marco del sistema capitalista, cuestiones que nos remiten también a cómo la ciudad se ha convertido en una mercancía (De Mattos, 2016, p. 29; Harvey, 2008, p. 31).

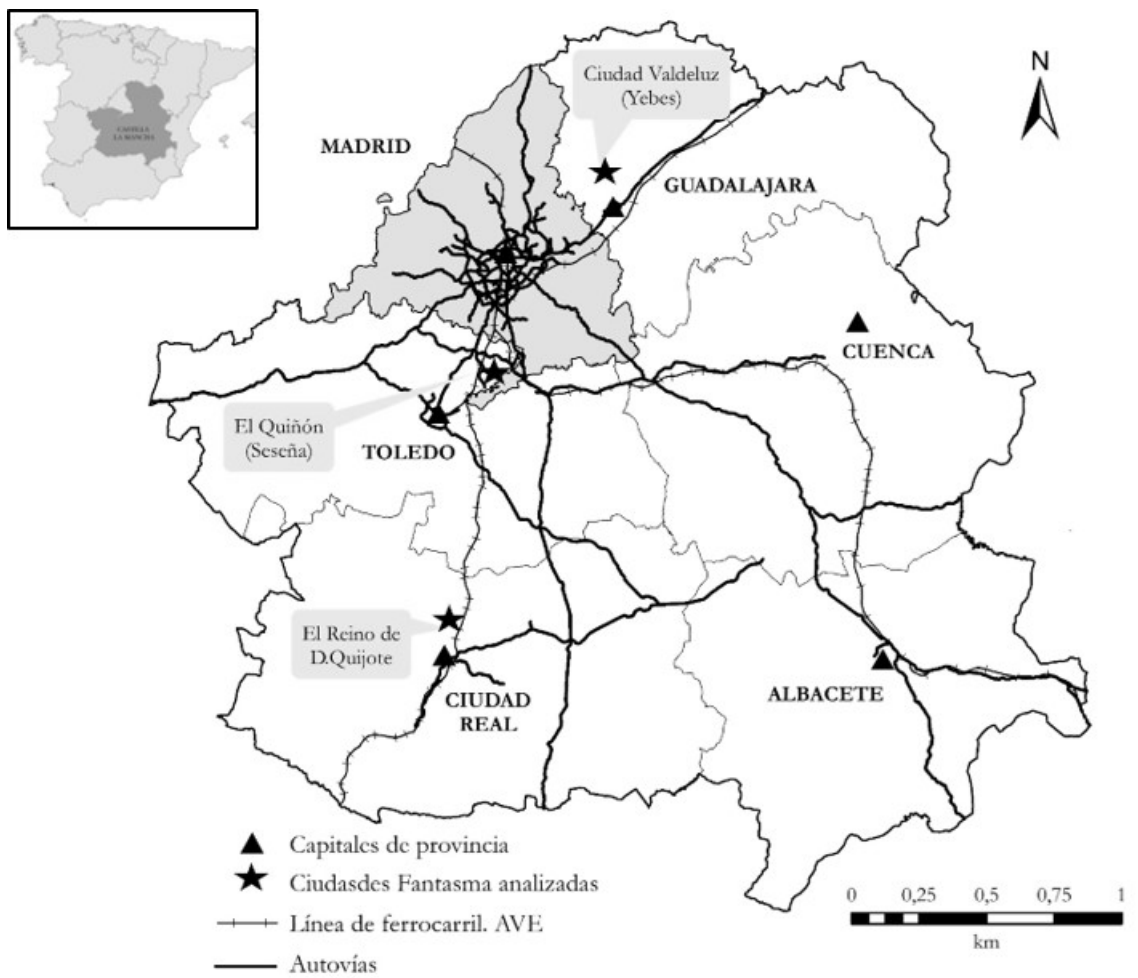

Figura I | “Ciudades fantasma” analizadas en Castilla-La Mancha (España) FUENTE: ELABORACIÓN PROPIA

Localizados en la siguiente cartografía (figura 1), los casos analizados son, en general, megaproyectos de promoción inmobiliaria en los que la clave del negocio ha sido comprar o disponer de suelo rústico, conseguir reclasificarlo como urbanizable y convertirlo en urbano, ańadiendo con este simple hecho varios ceros a su valor, acentuado con ello el modelo de edificación difusa o dispersa (Prada, 2010, p. 49). 
Son ejemplos de un crecimiento urbanístico desmedido, desordenado y no dirigido hacia los intereses generales, sino por el ánimo de lucro de algunos promotores y empresas. Son "desiertos urbanísticos" (Valenzuela, 2016, p. 231) creados por la irresponsable política urbanística expansiva compartida por numerosos municipios españoles y amparada o, al menos, consentida por las instituciones. En las proximidades de la capital del país, Madrid, encontramos algunos de los ejemplos más significativos a escala nacional, que hemos analizado a partir de bases metodológicas que combinan la revisión bibliográfica (incluidos los artículos de prensa) sobre los casos escogidos, con la revisión de la planificación regional y local, junto con las fuentes estadísticas básicas sobre población, suelo urbano y viviendas.

\section{Análisis de los casos de estudio y principales resultados}

A continuación sintetizamos las principales características de los casos más relevantes.

1. El primero que destaca, por su importancia internacional, medida según la atención mediática suscitada, es la Urbanización El Quiñón, en el núcleo de Seseña Nuevo ( 4915 hab. en 2017), en las proximidades de la ciudad de Seseña (22.992 hab. en 2017), asentamiento tradicional compacto. Es fruto de la clasificación de terrenos rústicos en urbanizables y urbanos donde los nuevos desarrollos se han generado fuera de los tradicionales límites urbanos (Pozo \& Cebrián, 2016, p. 251 y ss.). El Quiñón (1.822.147 $\mathrm{m}^{2}$ ) se diseñó, en 2004, para más de 15 mil viviendas (multifamiliares y en bloques de 9 y 10 plantas), construidas cuando la ciudad principal, Seseña, solo albergaba 7621 habitantes y se localiza en el eje de comunicación viaria de la A-4 (autovía que conecta la capital con Andalucía) a unos $30 \mathrm{~km}$ de Madrid. Se trata de un excelente ejemplo de ciudad inconclusa, ciudad fantasma o de "persianas bajadas" (Pozo \& Cebrián, 2016, p. 273), como podemos observar en la figura 2. En un contexto político muy complejo, con cambios continuos en el poder municipal, es consecuencia de sucesivos Planes de Actuación Urbanística (PAU) municipales (el primero de ellos de 2003, cuando el Ayuntamiento adjudicó el PAU de El Quiñón a la empresa Obras Nuevas de Edificación (ONDE) 2000 s.L., con uso residencial a partir de viviendas multifamiliares y edificios en open planning de 9 y 10 plantas). Ocurrieron, además, numerosas irregularidades, algunas conocidas por la prensa nacional, debido a la progresiva recalificación de suelo y las prácticas de edificación anteriores a la propia urbanización, paralizadas periódicamente por ausencia de servicios (suministro de agua) y donde el propio promotor, Francisco Hernando "El Pocero", debió pagar una deuda adquirida con la Administración Pública.

Los porcentajes de proyección de crecimiento que se estimaron en población $(174,9 \%)$ y en viviendas $(330,2 \%)$, con respecto a su núcleo más próximo (Seseña), donde existían ya 11.859 viviendas en 2011, ejemplifican una propuesta desmesurada (tabla 2). Ella constituye un claro ejemplo de especulación del suelo antes de la crisis y de desierto urbanístico después, donde la mayor parte de los compradores adquirieron su vivienda no como primera residencia, 
sino como inversión. Sobre una previsión de construcción de 15 mil viviendas, se han levantado 5096. Hasta el año 2011 se estimó que vivían 2300 vecinos, es decir, la mayoría de casas edificadas estaban sin habitar y en manos de las entidades acreedoras (bancarias preferentemente). La crisis paralizó la venta de viviendas, que se reactivó a partir de 2011, favorecida por los precios ofrecidos por las entidades bancarias que las habían adquirido durante la crisis y querían deshacerse de los inmuebles (Sanz, 2015). Es por ello que los datos actuales contemplan un cierto crecimiento demográfico, con signos de revitalización en una ciudad fantasma que empieza a revivir (Salido, 2016), asociada a las buenas conexiones con Madrid. Aún no se han cubierto las expectativas, ni creemos que se vayan a cubrir nunca, de manera que Seseña ha sido uno de los municipios españoles que ha sufrido un mayor impacto urbanístico, lo cual marcará su desarrollo futuro, ya que se ha modificado de forma sustancial su estructura urbana.

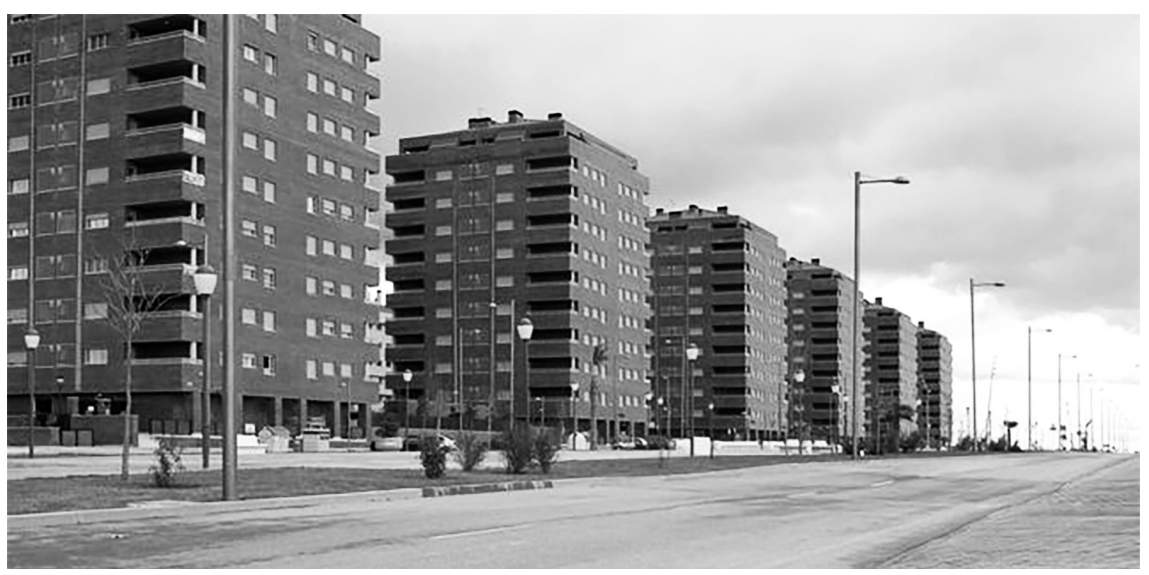

Figura 2 Bloques de viviendas en Seseña Nuevo (Toledo)

FUENTE: FOTOGRAFÍA DE LAS AUTORAS (2016)

\begin{tabular}{|l|c|c|c|c|}
\cline { 2 - 5 } \multicolumn{1}{c|}{} & \multirow{2}{*}{ SESEÑA } & \multicolumn{3}{c|}{ EL QUIÑóN (SESEÑA) } \\
\cline { 3 - 5 } \multicolumn{1}{c|}{} & & PROYECCIÓN & $\begin{array}{c}\text { \% RESPECTO A } \\
\text { SESEÑA }\end{array}$ & REALIDAD \\
\hline Población & 22.992 & 40.000 & $173,9 \%$ & 7.621 \\
\hline Suelo urbano (ha) & 7.268 & 182,2 & $2,5 \%$ & $*$ \\
\hline Viviendas & 11.859 & 15.000 & $330,2 \%$ & 5.096 \\
\hline
\end{tabular}

TABLa 2 | Datos urbanísticos de El Quiñón y Seseña (2017)

FUENTE: ELABORACIÓN PROPIA A PARTIR DE DATOS TERRITORIALES DE LAS FICHAS MUNICIPALES DEL INE (2OI7). * SIN DATOS 
2. El megaproyecto urbanístico Ciudad Valdeluz, en el municipio de Yebes (3076 hab. en 2017) dentro de la provincia de Guadalajara, se localiza en una de las áreas más altamente industrializadas del territorio limítrofe entre las Comunidades de Madrid y de Castilla-La Mancha, el Corredor del Henares, articulado en torno a la Autovía A-2 (Madrid-Valencia) y la red de Alta Velocidad Ferroviaria (Madrid-Barcelona-Frontera francesa). De hecho, la estación ferroviaria no se localiza en la capital provincial, Guadalajara, ni en el núcleo de Yebes, sino a $5 \mathrm{~km}$ de este, al lado de esta ciudad fantasma (figura 3), con barreras topográficas y ambientales que las separan y que hacen difícil pensar en una posible articulación física entre ellas. Responde a una decisión ferroviaria, según criterios de trazado y de economía, donde no se valoran las necesidades urbanísticas locales (Bellet, 2009, p. 159). Surgió inicialmente a partir del Plan Parcial "Estación AVE", dentro del Avance del Plan de Ordenación Municipal (РОм) de Guadalajara, aprobado en enero de 2009, y del Plan Parcial del Sector 1 del ром de Yebes, de abril de 2002, después modificado en junio de 2007, con lo que el suelo ha sido progresivamente recalificado, con viviendas de bloques en open plannig (figura 3), junto con unifamiliares.

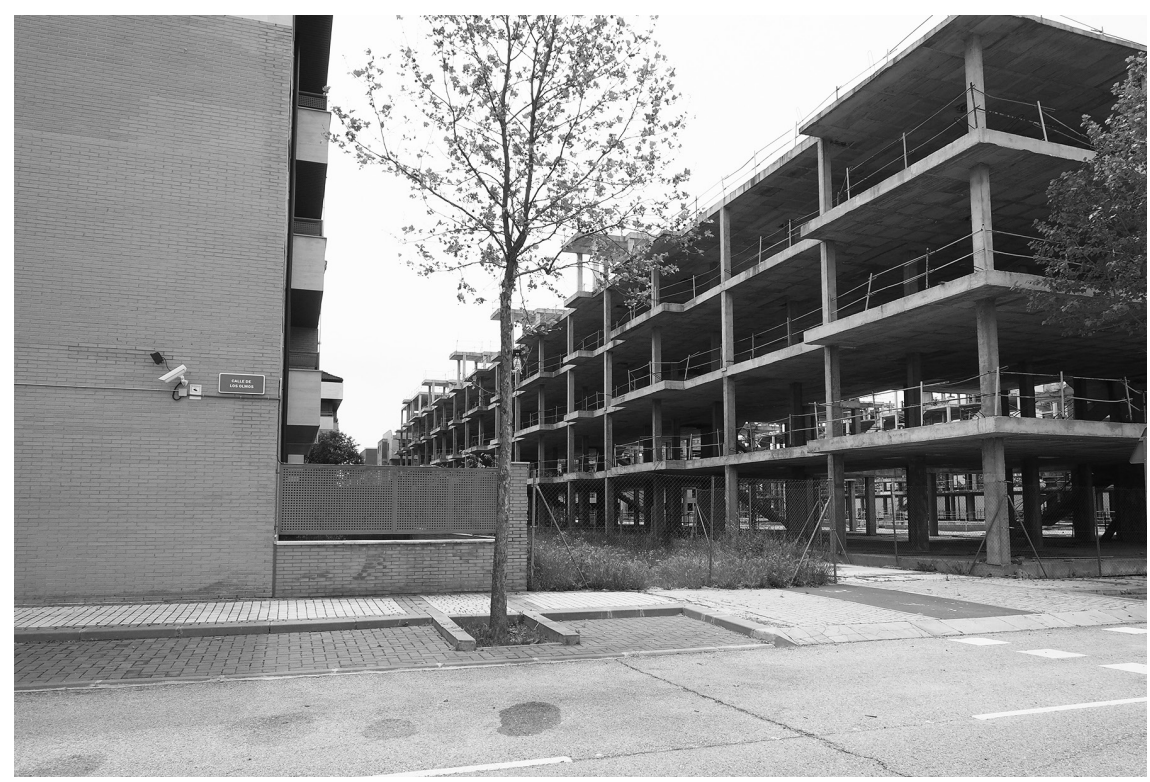

FIGURA 3 | Viviendas inacabadas en Ciudad Valdeluz (Guadalajara)

FUENTE: FOTOGRAFÍA DE LAS AUTORAS (20I6)

Ciudad Valdeluz se desarrolla asociada a esta infraestructura ferroviaria que hoy podemos calificar de infrautilizada y transforma el paisaje rural preexistente, al proyectar 9500 viviendas con una superficie de edificabilidad de $1.150 .000 \mathrm{~m}^{2}$, incluyendo dos campos de golf de 18 hoyos, un centro comercial y varios colegios. Con una expectativa de crecimiento de alrededor de 30 mil habitantes -es 
decir, un $975 \%$ respecto a su núcleo más próximo, Yebes, con 3076 habitantes en 2018 (INE, 2019)-, y con una prospectiva de viviendas desproporcionada -un 400\% sobre el parque de viviendas existente (2374 en 2011) (tabla 3)-, este caso constituye un buen ejemplo, como otros en España, de la irrupción de la urbanización en el medio rural con un papel de distorsionador de la economía agraria (Valenzuela, 2016, p. 230). A pesar de que los promotores afirmaran que su oportunidad territorial no solo se sustentaba en la estación de alta velocidad, sino también en la cercanía del aeropuerto de Barajas y del futuro aeropuerto de Campo Real, en el dinamismo del Corredor del Henares y en la posibilidad de ofrecer nueva vivienda muy cercana a Madrid (Bellet, 2009, p. 160), la realidad se aleja bastante del planteamiento inicial. En la actualidad cuenta con un centro médico, un supermercado (fruto de un acuerdo cerrado, ambos de carácter provisional) y un colegio. Albergaba 2316 habitantes en 2018 (INE, 2019), el 75,2\% de los habitantes del municipio de Yebes.

\begin{tabular}{|l|c|c|c|c|}
\cline { 3 - 5 } \multicolumn{1}{c|}{} & \multirow{2}{*}{ YEBES } & \multicolumn{3}{c|}{ CIUDAD VALDELUZ (YEBES) } \\
\cline { 3 - 5 } \multicolumn{1}{c|}{} & & PROYECCIÓN & $\begin{array}{c}\text { \% RESPECTO A } \\
\text { YEBES }\end{array}$ & REALIDAD \\
\hline Población & 3.076 & 30.000 & 975,3 & 2.316 \\
\hline Suelo urbano (ha) & 1.740 & 339 & 19,5 & $*$ \\
\hline Viviendas & 2.374 & 9.500 & 400,2 & 5.096 \\
\hline
\end{tabular}

TABLA 3 Datos urbanísticos de Ciudad Valdeluz y Yebes

FUENTE: ELABORACIÓN PROPIA A PARTIR DE DATOS TERRITORIALES DE LAS FICHAS MUNICIPALES DEL INE (2OI7). * SIN DATOS

3. El proyecto Gran Resort El Reino de Don Quijote se localiza a $5 \mathrm{~km}$ de Ciudad Real, capital con 74.743 habitantes en 2018 (INe, 2019). Está vinculado a dos grandes infraestructuras de comunicación: la línea de Alta Velocidad Ferroviaria (Sevilla-Madrid-Barcelona) y el Aeropuerto Central Ciudad Real, actualmente paralizado. Su origen se encuentra en la propuesta de sus propietarios al Ayuntamiento de instalar un complejo residencial-industrial a partir de suelo urbanizable programado, que después se reorientaría hacia un parque temático, primero, y luego un complejo de ocio-residencial (Pillet, 2005, p. 330). Para ello, inicialmente, en el Plan General de Ordenación Urbana de Ciudad Real, de 1997, se calificó como suelo de uso residencial-industrial una superficie de 1200 ha, a lo que se añadió la catalogación de Proyecto de Singular Interés (PSI) por el gobierno regional en 2003 y de Utilidad Pública e Interés Social, por la administración local. Sin embargo, realmente se buscaba la recalificación del terreno para vincularlo a urbanizaciones de segunda residencia a gran escala (Cañizares \& Rodríguez, 2014, p. 13), con la proyección, en 2003, de más de 3148 viviendas (primera fase), lo que lo convertía en uno de los principales desarrollos residenciales de la ciudad, de las 9 mil viviendas previstas en 18 ańos, con casi 2 mil de promoción pública (VPP). Esta proyección de viviendas hubiera 
supuesto un 23,7\% de las existentes en Ciudad Real (38.005) y un crecimiento demográfico del 53,6\% (tabla 4).

\begin{tabular}{|l|c|c|c|c|}
\cline { 3 - 5 } \multicolumn{1}{c|}{} & \multirow{2}{*}{ CIUDAD REAL } & \multicolumn{3}{|c|}{ EL REINO DE DON QUIJOTE (CIUDAD REAL) } \\
\cline { 3 - 5 } & & PROYECCIÓN & $\begin{array}{c}\text { \% RESPECTO A } \\
\text { CIUDAD REAL }\end{array}$ & REALIDAD \\
\hline Población & 74.641 & 40.000 & 53,6 & 0 \\
\hline Suelo urbano (ha) & 28.498 & 1.200 & 4,2 & $*$ \\
\hline Viviendas & 38.005 & 9.000 & 23,7 & 0 \\
\hline
\end{tabular}

Tabla 4 | Datos urbanísticos de El Reino de Don Quijote y Ciudad Real (2017)

FUENTE: ELABORACIÓN PROPIA A PARTIR DE DATOS TERRITORIALES DE LAS Fichas MUNICIPALES DEL INE (2017). * SIN DATOS

Su promotor, la empresa Valcansado S.A., del grupo inmobiliario Gedeco, pretendió combinar ofertas tanto residenciales como de golf, ocio, turismo, cultura y comercio, utilizando, como símbolo, la figura universal de Don Quijote. En 2009 fue asumido por la administración regional, al tratarse de un Proyecto de Singular Interés y el Ayuntamiento aprobó el Plan de Actuación Urbanística (PAU) para construir 2064 viviendas, hoteles y un gran casino, actualmente paralizado. Hoy conforma otra de las ciudades fantasma de la región, donde no ha habido desarrollo residencial, y constituye un buen ejemplo de paisaje paralizado o stand-by landscape (Concheiro, 2014, p. 4 y s.), en proceso de tramitación o carente de financiación (figura 4).

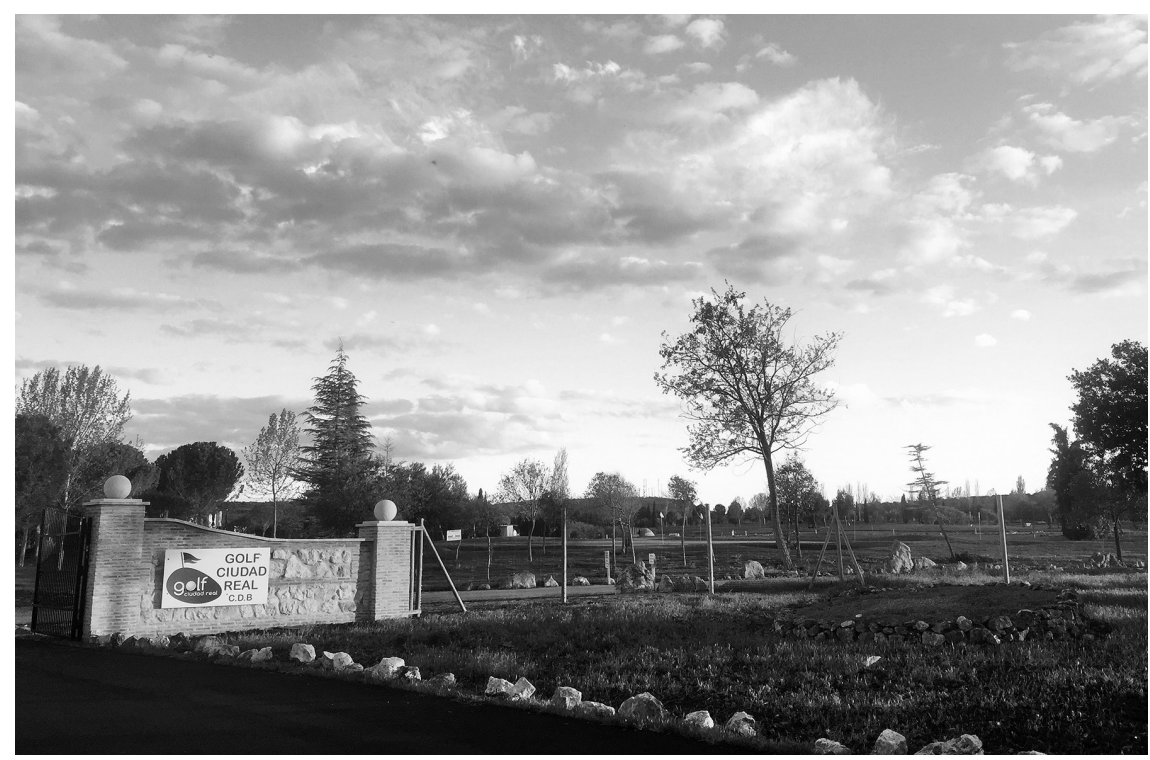

Figura 4 | El Reino de Don Quijote Golf en Ciudad Real (Ciudad Real) FUENTE: FOTOGRAFía DE LAS AUTORAS (20I6) 


\section{Discusión y conclusiones}

Podemos afirmar, a partir de las fuentes disponibles, que en Castilla-La Mancha las áreas cercanas al área metropolitana de Madrid han experimentado, como otros territorios españoles, un urbanismo expansivo y especulador basado en las inversiones inmobiliarias. Uno de los efectos más evidentes ha sido la aparición de diversas ciudades fantasma, las cuales, siguiendo la definición de Shepard (2015) anteriormente utilizada, se han correspondido con desarrollos urbanos sobredimensionados, algo evidente en los tres casos escogidos, que presentan unas señas de identidad comunes:

- Son fruto de una fuerte especulación urbanística en áreas rurales próximas a infraestructuras de comunicación (transporte de alta capacidad).

- Se desarrollan en espacios que presentan debilitamiento poblacional, en los que la especulación urbanística se ofrece como alternativa al declive demográfico.

La planificación territorial, potencialmente correctora, es muy débil en la región de Castilla-La Mancha. Es la planificación urbanística, en manos de las Administraciones locales (ayuntamientos), la responsable del aumento del suelo urbanizable, fruto -en ocasiones- de los confinamientos socioeconómicos de los núcleos y de las fuertes presiones recibidas por propietarios inversores.

Los ejemplos aquí analizados son una consecuencia del ciclo de urbanismo expansivo consolidado en el cambio de siglo, materializado en nuevas formas urbanas absolutamente desproporcionadas, que hoy se concretan en espacios inconclusos y viviendas vacías. Corregir las consecuencias de la urbanización excesiva y falsa prosperidad requerirá ańos de reforma y la reformulación de un sistema fallido que, además, representa un paso atrás en el bienestar social y exige un periodo de reflexión sobre la crisis ética y democrática (López \& González, 2014, p. 215). Consideramos, pues, que son suficientemente significativas para ejemplificar prácticas urbanísticas erróneas dentro de un contexto, el español, que ha presentado ciertas singularidades relacionadas con el giro neoliberal en las políticas, la bonanza económica y la especulación del suelo, así como con los efectos retardados de la crisis económica mundial. Con gran protagonismo en las zonas cercanas a áreas metropolitanas, sus patrones de localización y desarrollo presentan rasgos comunes. Entre ellos, su carácter de actuaciones estratégicas diseñadas a partir de proyectos de infraestructuras de comunicación (autovías, vías de ferrocarril aeropuertos), con sobredimensión de las necesidades residenciales esperadas. Acompaña y refuerza estos rasgos una planificación urbana absolutamente permisiva, y la ausencia de una planificación supramunicipal capaz de coordinar y controlar este tipo de desarrollos urbanísticos, lo cual ha generado complejas situaciones de un gran coste medioambiental.

Desde la disciplina geográfica, el documento Territorio, urbanismo y crisis (vv. AA., 2009) advirtió que la crisis podía servir para avanzar hacia la sostenibilidad y aprovechar las oportunidades (rehabilitar, reconstruir, recuperar...), pero también para retroceder, ya que los riesgos de "expandir innecesariamente la urbanización" 
determinarían, entre otras cuestiones, "prestar menor atención a la ciudad existente para atender pretendidas necesidades de expansión urbana, no siempre justificadas”. Se hace necesario, pues, avanzar hacia una nueva hoja de ruta en las políticas urbanas tal y como plantean Romero, Brandis y Melo (2015, p. 380), en la que se busque: i) reducir la "fractura social" y, por tanto, las desigualdades; ii) reducir la "brecha política" entre ciudadanos y partidos políticos; y iii) impulsar modelos de crecimiento equilibrados que tengan en cuenta la escala metropolitana (aspecto relevante en el caso de los espacios urbanos de Castilla-La Mancha respecto a Madrid). En otras palabras, replantear el modelo de desarrollo urbano bajo parámetros de sostenibilidad, evitando la dispersión, según los cuales la vivienda responda a las necesidades de la sociedad y no a los intereses del capital privado.

Las propuestas que Gaja (2012, p. 113 y ss.) planteó para el caso valenciano pueden servir para Castilla-La Mancha: congelar el producto a la espera de la reabsorción por parte del mercado, abandonar los espacios, desurbanizarlos o reutilizarlos para otros usos, y rentabilizar y vender las viviendas vacías. De hecho, la reutilización permitiría acceder a una vivienda digna a quienes ahora están privados de ese derecho, aunque las pérdidas que esto generaría en el sector bancario no permiten albergar grandes expectativas.

Resulta ineludible avanzar hacia un mejor pensamiento de la ciudad, dada la actual realidad financiera, social y residencial (Cebrián, Piñeira, \& González-Pérez, 2019, p. 1 y ss.). Es necesario elaborar nuevos planes, incluyendo en el planeamiento urbanístico tradicional las directrices y conclusiones de la planificación estratégica, como ya planteó el geógrafo Pillet (2012, p. 46), así como incluir la sostenibilidad en el modelo urbano. Solo mediante el diseño de desarrollos con altas densidades, la concentración a lo largo de corredores de transporte público y el fomento de usos del suelo mixtos, se alcanzará una forma urbana sostenible (Davoudi \& Sturzaker, 2017, p. 59), algo bastante alejado de lo aquí expuesto.

\section{Agradecimientos}

Este artículo se inscribe en el marco de dos Proyectos de Investigación: "Análisis y caracterización de las diez Áreas Funcionales Urbanas y su relación con la cohesión territorial" (2014-2016) (PEII-20 I 4-006-P). Junta de Comunidades de Castilla-La Mancha; y "Dinámicas de urbanización y políticas urbanísticas en ciudades medias interiores. De expansión y difusión a reformulación ¿ Hacía un urbanismo más urbano?” (2015-2018) (CSO20 I 5-63970-R). Plan Nacional de I+D+I. 


\section{Referencias bibliográficas}

Aalbers, M. B. (2016). The financialization of housing. New York: Routledge.

Batty, M. (2014). At the crossroads of urban growth. Environment and Planning B: Planning and Design, 41, 951-953. https://doi.org/10.1068/b4106ed

Batty, M. (2016). Empty buildings, shrinking cities and ghost towns. Environment and Planning B: Planning and Design, 43(1), 3-6. https://doi.org/10.1177/0265813515619858

Bellet, C. (2009). La alta velocidad y el medio urbano en el siglo xxi. En I. Caravaca, I. Fernández Salinas, \& R. Silva (coords.), Ciudades, culturas, fronteras en un mundo en cambio (pp. 136-171). Sevilla: Asociación de Geógrafos Españoles (AGE) / Universidad de Sevilla.

Berry, B. J. L. (1976). Urbanization and counter-urbanization. New York: SAge Publications.

Brandis, D. (2012). El estancamiento de los últimos desarrollos urbanos de la periferia madrileña. Crisis inmobiliaria y estrategias de ordenación. En Á. Miramontes, D. Royé, \& J. I. Vila (coords.), Las ciudades y el sistema urbano. Reflexiones en tiempos de crisis (pp. 111-120). La Coruña: Meubook.

Burgen, S. (2015). Welcome to Don Quixote airport: cost $€ 1$ bn - now it could sell to China for $€ 10,000$. The Guardian, New York (17/07/2015). http://www.theguardian.com/ world/ 2015/jul/17/don-quixote-airport-building-cost-1bn-sold-china-10000

Burriel, E. (2008). La "década prodigiosa" del urbanismo español (1997-2006). Scripta Nova. Revista Electrónica de Geografía y Ciencias Sociales, 1 de agosto, 12(270/64). https://doi. org/10.1344/sn2008.12.1489

Burriel, E. (2014). El estallido de la burbuja inmobiliaria y sus efectos en el territorio. En J. M. Albertos \& J. L. Sánchez (coords.), Geografía de la crisis económica en España (pp. 101-140). Valencia: Universitat de Valéncia.

Burriel, E. (2016). Empty urbanism: the bursting of the Spanish housing bubble. Urban Research \& Practice, 9(2), 158-180. http://dx.doi.org/10.1080/17535069.2015.1110 196

Calderón, B. (2004). La ciudad del todo urbanizable: estrategias del sector inmobiliario y nuevas e insostenibles formas de urbanización. Ciudades, (8), 135-155. https://doi. org/10.24197/ ciudades.08.2004.135-155

Cañizares, M.C. \& Martínez, H. S. (2014). Ciudad Real y Puertollano: áreas funcionales urbanas (FUA) y policentrismo en Castilla-La Mancha (España). Documents d'Anàlisi Geogràfica, 60(1), 31-55. https://doi.org/10.5565/rev/dag.79

Cañizares, M. C. \& Rodríguez, M. Á. (2014). Ciudad Real y “El Reino de Don Quijote”: un megaproyecto urbanístico paralizado por la crisis. XII Coloquio y Trabajos de Campo del Grupo de Geografia Urbana de la Asociación de Geógrafos Españoles. Madrid y CastillaLa Mancha, 11-14 de junio, 2014. https://bit.ly/2ny11yv

Cañizares, M. C. \& Rodríguez, M. Á. (2017). Castilla-La Mancha y sus nuevos escenarios urbanos: las ciudades fantasma. En M. Castanyer Vivas, J. Vicente i Rufi, J. Feliu Torrent \& J. Martín Uceda (eds.), Nuevos escenarios urbanos: nuevos conflictos y nuevas politicas. XIII Coloquio de Geografía Urbana (pp. 53-74). Girona: Asociación de Geógrafos Españoles (AGE) / Documenta Universitaria, Universitat de Girona. https:// www.age-geografia.es/site/wp-content/uploads/2014/11/Geografia_Urbana.pdf

Capel, H. (1975). Capitalismo y morfología urbana en España. Barcelona: Libros de Cordel. 
Capel, H. (2009). Las pequeñas ciudades en la urbanización generalizada y ante la crisis global. Investigaciones Geográficas, (70), 7-32. https://www.redalyc.org/articulo. oa?id $=56912238002$

Capel, H. (2013). Crisis de los modelos urbanos. Una mirada hacia el futuro. Mercator, 12(2), 7-27. http://dx.doi.org/10.4215/RM2013.1202.0001

Caravaca, I., González-Romero, G., \& López, P. (2017). Crisis y empleo en las ciudades españolas. EURE, 43(128), 31-54. http://dx.doi.org/10.4067/S0250-71612017000100002

Cebrián, F. (2007). Ciudades con límites y ciudades sin límites. Manifestaciones de la ciudad difusa en Castilla-La Mancha. Boletín de la Asociación de Geógrafos Españoles, (43), 221-240. http://dx.doi.org/10.21138/bage.589

Cebrián, F. (2013). Las transformaciones recientes operadas en las periferias de las ciudades medias. El contexto de la ciudad difusa en la realidad espańola. En F. Cebrián \& M. Panadero (coords.), Ciudades medias. Formas de expansión urbana (pp. 25-38). Madrid: Biblioteca Nueva.

Cebrián, F. \& García, J. A. (2011). Las dinámicas del urbanismo difuso en los entornos de las ciudades en las ciudades de Castilla-La Mancha. En V. Gonzálvez \& J. A. Marco (eds.), Urbanismo expansivo: de la utopia a la realidad (pp. 131-142). Alicante: Universidad de Alicante / Asociación de Geógrafos Españoles (AGE).

Cebrián, F., García, J. A., \& Panadero, M. (2009). Los territorios de la suburbanización en Castilla-La Mancha. Análisis a escala municipal. En I. Caravaca, I. Fernández Salinas, \& R. Silva (coords.), Ciudades, culturas, fronteras en un mundo en cambio (pp. 114126). Sevilla: Asociación de Geógrafos Españoles (AGE) / Universidad de Sevilla.

Cebrián, F., Piñeira, M. J., \& González-Pérez, J. (2019). Readings of the post-crisis Spanish city: between social inequity and territorial destruction. Urban Science, 3(43), 1-7. http://dx.doi.org/10.3390/urbansci3020043

Chakrabortty, A. (2011). Nightmare for residents trapped in Spanish ghost towns. The Guardian, New York (28/03/2011). http://www.theguardian.com/world/2011/ mar/28/residents-trapped-spanish-ghost-towns

Concheiro, I. (2014). Interrupted Spain. Los paisajes especulativos de la burbuja inmobiliaria. En D. Bradis García, M. I. del Río Lafuente, \& G. Morales Matos (coords.), Estudios de geografia urbana en tiempos de crisis. Territorios inconclusos y sociedades rotas en España. XII Coloquio y Trabajos de Campo del Grupo de Geografía Urbana de la Asociación de Geógrafos Españoles (pp. 1-11). Madrid: Grupo de Geografía Urbana / Asociación de Geógrafos Españoles (AGE).

Daher, A. (2013). Territorios de la financiarización urbana y de las crisis inmobiliarias. Revista de Geografia Norte Grande, (56), 7-30. http://dx.doi.org/10.4067/S071834022013000300002

Daley, S. \& Minder, R. (2010). Newly built ghost towns haunt banks in Spain (Yebes). The New York Times, New York (17/12/2010). http://www.nytimes.com/2010/12/18/ world/europe/18spain.html?_r=0

Davoudi, S. \& Sturzaker, J. (2017). Urban form, policy packaging and sustainable urban metabolism. Resources, Conservation and Recycling, 120, 55-64. https://doi. org/10.1016/j.resconrec.2017.01.011

De Mattos, C. A. (2015). Revolución urbana. Estado, mercado y capital en América Latina. Santiago, Chile: Colección Estudios Urbanos UC / RIL Editores. 
De Mattos, C. A. (2016). Financiarización, valorización inmobiliaria del capital y mercantilización de la metamorfosis urbana. Sociologias, 18(42), 24-52. http://dx.doi. org/10.1590/15174522-018004202

De Mattos, C. A., Fuentes, L., \& Link, F. (2014). Tendencias recientes del crecimiento metropolitano en Santiago de Chile. ¿Hacia una nueva geografía urbana? Revista INVI, 29(81), 193-219. http://dx.doi.org/10.4067/S0718-83582014000200006

Delgado, C. (2016). Miradas de la ciudad desde la Geografía, la Historia y el Urbanismo. El estado de la cuestión a comienzos del siglo xxi. Ciudades, 19(1), 117-142. https://doi. org/10.24197/ciudades.19.2016.117-142

Duhamel, F. \& Trápaga, Y. (2015). Cuestión de política económica: Ciudades fantasma en China y México. En Y. Trápaga (coord.), América Latina y el Caribe y China. Recursos naturales y medio ambiente 2015 (pp. 79-98). México: Unión de Universidades de América Latina y el Caribe.

Fernández, R. (2006). El tsunami urbanizador español y mundial. Madrid: Virus Editorial.

Fernández-Tabales, A. \& Cruz, E. (2013). Análisis territorial del crecimiento y la crisis del sector de la construcción en España y la Comunidad Autónoma de Andalucía. EURE, 39(116), 5-37. http://dx.doi.org/10.4067/S0250-71612013000100001

Gaja, F. (2008). El "tsunami urbanizador" en el litoral valenciano. El ciclo de hiperproducción inmobiliaria 1996-2006. Scripta Nova. Revista de Geografia y Ciencias Sociales, 1 de agosto, 12(270/66). http://dx.doi.org/ 10.1344/sn2008.12.1491

Gaja, F. (2012). Antes, durante y después del tsunami inmobiliario en el País Valenciano. En F. Gaja (ed.), Deconstruction. La desconfiguración del litoral mediterráneo español (pp. 78-126). Valencia: Universitat Politècnica de València.

Gaja, F. (2013). Tras el tsunami inmobiliario. Salir del atolladero. En Observatorio Metropolitano, Paisajes devastados después del ciclo inmobiliario (pp. 313-354). Madrid: Traficantes de Sueños.

Gaja, F. (2015). Urbanismo concesional. Modernización, privatización y cambio de hegemonía en la acción urbana. Ciudades, (18), 103-126. https://doi.org/10.24197/ ciudades.18.2015.103-126

Goldman, L. \& Lubin, G. (2011). Amazing satellite images of Spanish ghost towns - Abandoned since the crash. The Bussines Insider, 27/05/2011. http://www.businessinsider.com/ spain-ghost-towns-satellite-2011-4

Gotham, K. F. (2009). Creating liquidity out of spatial fixity: The secondary circuit of capital and the subprime mortgage crisis. International Journal of Urban and Regional Research, 33(2), 355-371. https://doi.org/10.1111/j.1468-2427.2009.00874.x

Harvey, D. (2008). El derecho a la ciudad. New Left Review, (53), 23-39. https://newleftreview. es/issues/53/articles/david-harvey-el-derecho-a-la-ciudad.pdf

Hernández, M.A. (2007). Urbanismo y depredación del territorio en Castilla-La Mancha. Ciudad Real: Ecologistas en Acción Castilla-La Mancha.

Hortas-Rico, M. (2014). Urban sprawl and municipal budgets in Spain: A dynamic panel data analysis. Papers in Regional Science, 93(4), 843-865. https://doi.org/10.1111/ pirs. 12022

Instituto Nacional de Estadística (INE), España (2019). Datos estadísticos. https://www.ine.es/ 
Junta de Comunidades de Castilla-La Mancha (JCCM). (2018). Estadísticas precio vivienda por metro cuadrado. http://www.ies.jccm.es/estadisticas/de-coyuntura/construccion/ precios-de-la-vivienda/

Lois, R. C., Piñeira, M. J., \& Vives, S. (2016). El proceso urbanizador en España (1990-2014): una interpretación desde la Geografía y la teoría de los circuitos del capital. Scripta Nova. Revista Electrónica de Geografía y Ciencias Sociales, 1 de julio, 20(539). https:// doi.org/10.1344/sn2016.20.16793

López, E. \& González, Z. (2014). Ghost cities and empty houses: Wasted prosperity. American International Journal of Social Science, 3(2), 207-216. http://www.aijssnet.com/ journals/ Vol_3_No_2_March_2014/23.pdf

McGovern, S. (2008): From boom town to ghost town. BBC news (27/08/2008). http://news. bbc.co.uk/2/hi/business/7584097.stm

Marichal, C. (2013). Nueva historia de las grandes crisis financieras. Una perspectiva global, 1873 2008. Buenos Aires: Debate.

Méndez, R. (2006). El dueño de la macrourbanización de Seseña ha contratado a concejales y técnicos municipales. El País, Madrid (30/072006). http://elpais.com/ diario/2006/07/30/ espana/1154210402_850215.html

Méndez, R. (2012). Globalización, neoliberalismo y dinámicas metropolitanas en Madrid. DAAPGE, (71), 99-127.

Méndez, R., Abad, L. D., \& Echaves, C. (2015). Atlas de la crisis. Impactos socioeconómicos y territorios vulnerables en España. Valencia: Tirant-Humanidades.

Méndez, R. \& Plaza, J. (2016). Crisis inmobiliaria y desahucios hipotecarios en España: una perspectiva geográfica. Boletín de la Asociación de Geógrafos Españoles, (71), 369-386. https://doi.org/10.21138/bage.2276

Ministerio de Fomento (2018). Estadísticas número de viviendas según tipo de obra. CastillaLa Mancha. Licencias. Evolución Histórica. Madrid. http://www.fomento.gob.es/BE/ sedal/10020730.XLSNaredo, J. M. (2010). El modelo inmobiliario español y sus consecuencias. Boletin CF+S, (44), 13-27.

Naredo, J. M. \& Relevante, U. E. (2015). La burbuja especulativa y la crisis inmobiliaria en perspectiva. Cuadernos de Investigación Urbanistica, (100), 77-82. https://doi. org/10.20868/ciur.2015.100.3168

Ocańa, C. (2009). Urbanización y vivienda, negocio financiero y conflicto social. En J. M. Feria, A. García, \& J. F. Ojeda (eds.), Territorios, sociedades y politicas (pp. 349-368). Sevilla: Asociación de Geógrafos Españoles (AGE) / Universidad Pablo de Olavide.

Nel.lo, O. (2017). El proceso de urbanización: motor y expresión de las transformaciones sociales y territoriales. En J. Romero (coord.), Geografía Humana de España (pp. $290-$ 364). Valencia: Tirant Humanidades / Universidad de Valencia.

Peck, J., Theodore, N., \& Brenner, N. (2009). Neoliberal urbanism: models, moments, mutations. SAIS Review, 29(1), 49-66. https://doi.org/10.1353/sais.0.0028

Pillet, F. (2005). Ciudad Real: cambios en el espacio público y en la vida colectiva con la llegada del AVE a la ciudad. En O. Gutiérrez (coord.), La ciudad y el miedo (pp. 325-334). Barcelona: Asociación de Geógrafos Españoles (AGE) / Universidad de Girona.

Pillet, F. (2012). Planificación Territorial. Propiedad y valoración catastral (España 1750-2010). Madrid: Biblioteca Nueva. 
Pillet, F. \& Cañizares, M. C. (coords.) (2017): Policentrismo y áreas funcionales de baja densidad. Madrid: Síntesis.

Pillet, F., Cañizares, M. C., Ruiz, A. R., Martínez, H. S., Plaza, J. J., \& Santos, J. F. (2010). El policentrismo en Castilla-La Mancha y su análisis a través de la población vinculada. Scripta Nova. Revista de Geografía y Ciencias Sociales, 20 de abril, 14(321). http:// dx.doi.org/10.1344/sn2010.14.1627

Pillet, F., Cañizares, M. C., Ruiz, A. R., Martínez, H. S., Plaza, J. J., \& Santos, J. F. (2014). Applying the European spatial development perspective in low-density regions: A methodology based on mobility and labour market structure. Urban Studies, 51(3), 577-595. https://doi.org/10.1177/0042098013498287

Pozo, E. \& Cebrián, F. (2016). Residencial Francisco Hernando. Una urbanización desmedida e inconclusa en Seseña (Toledo). En D. Brandis, I. del Río, \& G.M. Matos (eds.), Estudios de Geografía Urbana en tiempos de crisis. Territorios inconclusos y sociedades rotas (pp. 251-274). Madrid: Editorial Biblioteca Nueva.

Prada, E. (2010). Concentración espacial de la propiedad de la tierra, megaproyectos inmobiliarios y transformación del paisaje: caso Valdeluz. Ciudad y Territorio. Estudios Territoriales, (163), 49-66.

Rodríguez, M.A. (2011). Características del crecimiento urbano en Castilla-La Mancha durante el boom inmobiliario. En V. Gozálvez \& J. A. Marco (eds.), Urbanismo expansivo: de la Utopía a la realidad (pp. 593-604). Alicante: Universidad de Alicante / Asociación de Geógrafos Españoles (AGE).

Rodríguez, M. A. (2014). Paisajes urbanos de crisis, paisajes para la reflexión. El caso de Ciudad Real. Cuadernos de Estudios Manchegos, (39), 147-176. https://dialnet.unirioja.es/ servlet/articulo? codigo $=5284962$

Romero, J. (2010). Construcción residencial y gobierno del territorio en España. De la burbuja especulativa a la recesión. Causas y consecuencias. Cuadernos Geográficos, (47), 17-46. http://www.ugr.es/ - cuadgeo/docs/articulos/047/047-002.pdf

Romero, J., Brandis, D., \& Melo, C. (2015). El giro neoliberal de las políticas para la ciudad en España. Balance a partir de los ejemplos de Madrid y Valencia. Boletín de la Asociación de Geógrafos Españoles, (69), 369-386. http://dx.doi.org/10.21138/bage.1901

Rullán, O. (2012). Urbanismo expansivo en el Estado español: de la utopía a la realidad. En V. Gozálvez \& J. A. Marco (eds.), Geografía. Retos ambientales y territoriales (pp. 165209). Alicante: Universidad de Alicante / Asociación de Geógrafos Españoles (AGE).

Rullán, O. (2016). La planificación urbana y territorial en tiempos de crisis. En J. Olcina \& A. M. Rico (coords.), Libro jubilar en homenaje al profesor Antonio Gil Olcina (pp. 12671286). Alicante: Universidad de Alicante.

Salido, J. (2016). La recuperación inmobiliaria llega a la ciudad de "El Pocero" en Seseña. El Mundo. Madrid (22/04/2016). http://www.elmundo.es/ economia/2016/04/22/57190cbe468aeb39418b45ee.html.

Sanz, E. (2015). Seseña, cientos de viviendas en medio de la nada ocho años después. El Confidencial. Madrid (04/12)2015). http://www.elconfidencial.com/ vivienda/2015-12-04/sesena-cientos-de-viviendas-en-medio-de-la-nada-ocho-anosdespues-el-pocero $1112392 /$.

Shepard, W. (2015). Ghost cities of China: The story of cities without people in the world's most populated country. London: Zed Books. 
Valenzuela, M. (2013). Introducción a Las ciudades españolas en la encrucijada: entre el "boom" inmobiliario y la crisis económica (pp. 13-24). En M. Valenzuela (ed.), Madrid: Real Sociedad Geográfica / Asociación de Geógrafos Españoles (AGE). https://bit. ly/2nVCBpv

Valenzuela, M. (2016). Tendencias y desafíos de la planificación urbana y del gobierno del territorio. La perspectiva de los geógrafos españoles (2005-2015). En Comité Español de la Unión Geográfica Internacional, Crisis, globalización y desequilibrios sociales y territoriales en España (pp. 225-242). Madrid: Asociación de Geógrafos Españoles (AGE) / Real Sociedad Geográfica.

Valenzuela, M. \& Salom, J. (2008). Los procesos de urbanización en España. Nuevos factores, nuevas tendencias. En Comité Español de la Unión Geográfica Internacional, España y el Mediterráneo: una reflexión desde la geografía española. Aportación española al xxxi Congreso de la Unión Geográfica Internacional, Túnez 2008 (pp. 49-56). Madrid: Asociación de Geógrafos Españoles (AGE) y Real Sociedad Geográfica. http://www. uam.es/gruposinv/urbytur/documentos/procesosdeurbanizacion2008.pdf

Vives, S. \& Rullán, O. (2014). La apropiación de las rentas del suelo en la ciudad neoliberal española. Boletín de la Asociación de Geógrafos Españoles, (65), 387-408. http://dx.doi. org/10.21138/bage. 1758

vv.AA. (2006). Manifiesto "Por una Nueva Cultura del Territorio". Madrid. http://www. geografos.org/images/stories/interes/nuevacultura/manifiesto-por-una-nueva-culturadel-territorio-d5.pdf

vv.AA. (2009). Territorio, urbanismo y crisis. Madrid. [Firmado por Promotores del Manifiesto por una Nueva Cultura del Territorio, Presidente de la Asociación de Geógrafos Espańoles, Presidente del Colegio de Geógrafos]. https://nuevaculturadelterritorio. files. wordpress.com/2008/05/territorio_urbanismo_y_crisis.pdf

Vv.AA. (2011). Las 'ciudades fantasma' de la burbuja fascinan a la prensa extranjera. El Mundo, Madrid, 27 de mayo. http://www.elmundo.es/elmundo/2011/05/27/suvivienda/ 1306518138.html

Zheng, Q., Zeng, Y., Deng, J., Wang, K., Jiang, R., \& Ye, Z. (2017). Ghost cities identification using multi-source remote sensing datasets: A case study in Yangtze River Delta. Applied Geography, (80), 112-121. https://doi.org/10.1016/j.apgeog.2017.02.004 